\title{
Can smallholder avocado production reduce poverty and improve food security through internal markets? The case of Giheta, Burundi
}

\section{Hakizimana \& J. May}

To cite this article: C. Hakizimana \& J. May (2018) Can smallholder avocado production reduce poverty and improve food security through internal markets? The case of Giheta, Burundi, Forests, Trees and Livelihoods, 27:4, 203-216, DOI: 10.1080/14728028.2018.1515041

To link to this article: https://doi.org/10.1080/14728028.2018.1515041

曲 Published online: 10 Sep 2018.

Submit your article to this journal $\pi$

Џll Article views: 578

Q View related articles $\asymp$

View Crossmark data \lceil 


\title{
Can smallholder avocado production reduce poverty and improve food security through internal markets? The case of Giheta, Burundi
}

\author{
C. Hakizimana ${ }^{a}$ and J. May ${ }^{b}$
}

anstitute for Poverty, Land and Agrarian Studies (PLAAS), University of the Western Cape, Cape Town, South Africa; 'DST-NRF Centre of Excellence in Food Security and UNESCO Chair in African Food Systems, University of the Western Cape, Cape Town, South Africa

\begin{abstract}
The role of agriculture in rural development is widely documented in literature. Many analysts regard agriculture, specifically smallscale agriculture, as an effective instrument for poverty reduction and food security, particularly in rural communities of developing countries where large numbers of poor people are concentrated. However whether the focus of such production should be on export crops or for domestic food security remains an issue for debate. Using the avocado industry in Giheta-Burundi, this paper argues that some emerging tree crops such as avocados present enormous opportunities to income generation and food security for small-scale farmers. This paper suggests that small-scale avocado farming presents the economic, market and health potentiality to contribute to a viable and sustainable rural economy through internal markets thereby reducing levels of poverty and malnutrition in this area. From a policy perspective, the paper suggests that the avocado sector needs to be supported by both the private and public sectors, irrespective of whether the crop is consumed, traded domestically or exported. Increasing the capacity of avocado production and trade will then enable small-scale farmers and vendors to gain greater income from this sector.
\end{abstract}

\section{KEYWORDS}

Smallholder avocado production; food security; income generation; wellbeing; rural markets; value chain; institutional arrangements

\section{Introduction}

Promoting agricultural production and trade is being recommended as an important strategy for economic growth and poverty reduction (Larson et al. 2014). The OECD (2017) report entitled "Agricultural Policy Monitoring and Evaluation 2017" shows that very few economies have achieved sustainable economic growth without agricultural and rural growth preceding or accompanying it. However, most analysts agree that only small-scale agriculture can achieve a sustainable rural economic growth and its associated poverty reduction (Barrett et al. 2017). Identifying the characteristics and context of those agricultural activities that can contribute towards poverty reduction is then a critical issue and the focus of this paper. 
Avocado production in the commune of Giheta, Burundi is an interesting example with which to illustrate the role that agriculture could make in the context of high levels of poverty. Avocado is a comparatively recent introduction to Burundi, and potentially is both a cash and subsistence crop. Burundi's Human Development Index (HDI) value is 0.404, positioning it at 184 out of 188 countries (Human Development Report 2016). Employment in small-scale agricultural production is an important livelihood activity throughout the country, and in Giheta. The cultivation and sale of avocados is widespread in this commune.

The few available studies have confirmed the avocado crop's economic and market potentiality to stimulate rural development in developing countries (Gyau et al. 2016; Mwambi et al. 2016). Avocado production represents an opportunity to diversify the rural agricultural sector that, in developing countries, is often dominated by one or two cash crops such as coffee, cocoa or tea. These traditional cash crops are subject to declining prices and when not exported, are of little use to either the producers or consumers in the countries in which they are produced. Unlike most other cash crops, avocado high nutritional value makes the crop a potentially important nutritional food source (Tabeshpour et al. 2017). This quality positions this crop to also contribute towards improved food and nutritional security in poor countries. This paper takes advantage of these attributes to explore the extent to which the production of avocados benefit the income and well-being of small-scale farming households and the role that the public sector should play to support this.

\section{The role of agriculture in the process of economic growth and poverty reduction}

The role of agriculture in development remains contested. The debated perspectives are the role of agriculture in the structural transformation and poverty reduction. Advocates of agriculture as an engine of growth draw on seminal papers of Lewis (1954) and Johnston and Mellor (1961) that provided a conceptual argument for agriculture's role in the process of economic growth. Agricultural productivity growth is argued to increase rural income; lower food prices in urban areas which in turn lead to industrial competitiveness; increase savings in rural areas which generates strong economic linkages to the domestic agricultural linked industry and expand markets for non-agricultural goods and services (De Souza 2015; de Janvry and Sadoulet 2010; Chen and Liao 2015).

Poverty reduction is also argued to follow from agricultural productivity growth. Since poverty is concentrated in rural areas where livelihoods are predominantly garnered in the agricultural sector (Davis et al. 2014; Beegle et al. 2016), analysts argue that growth in this sector is most likely to reduce poverty and improve food security (Christiaensen and Kaminski 2015; Barrett et al. 2017).

A related debate concerns the relative merits of large and small farms and their implications for poverty reduction and economic growth (Collier and Dercon 2014). The distinctive role of smallholders in the process of economic development can be traced back to Schultz's (1964) argument of 'poor but efficient'. Output in the small-scale agriculture has been found to have positive effects on local economic linkages which stimulate the growth of labour-intensive non-agricultural economic activities in rural areas (Hakizimana et al. 2017; Matenga and Hichaambwa 2017; Yaro et al. 2017). Thus it is proposed that both growth and equity goals may be satisfied simultaneously through 
an emphasis on small-farm agriculture (Barrett et al. 2017). Supported by these arguments, the Pan-African Alliance for a Green Revolution in Africa also contended that food security and prosperity in Africa will only be achieved through the promotion of rapid agricultural growth based on small farms (AGRA 2011).

This paper takes a view that it is not any kind of agriculture that can achieve poverty reduction. Building on existing small-farm efficiencies appears to offer the greatest potential. Hence, the crop, its mode of production and trade, and the context in which it is being produced and traded will all have a role in determining the extent to which a reduction in poverty can be achieved. Avocado may represent a crop with such potential for Burundi.

\section{Avocado, growth and food security}

Avocado has been touted as "wonder fruit" in the popular press, and with some scientific justification. Avocado has been found to contain important vitamins and minerals associated with a range of health benefits including overweight, cancer, heart disease and arthritis (Tabeshpour et al. 2017), and both theory and empirical evidence seem to suggest that eating avocadoes may indeed contribute to solving many health problems (Tabeshpour et al. 2017).

These nutritional values of avocado have led the Australian Heart Foundation to certify this fruit as a "heart-healthy" food and it is classified by the American Dietetic Association as a "functional food" with many health benefits (Perez-Jimenez 2008). Additionally, avocado oil is valued by the cosmetic industry due to the presence of a natural sterol that has the same penetrating abilities as lanolin. It is used as a skin moisturizer, cleansing cream, makeup base, sun screen, lipstick, bath oil, hair conditioner and as an input in the food industry (Rodríguez-Carpena et al. 2011).

Avocado is an important crop to rural communities and economies in East Africa (Gyau et al. 2016; Mwambi et al. 2016). As an example, between 2003 and 2013, avocado production in Kenya almost tripled, from 70,948 tons in 2003 to 191,505 tons in 2013 and the area under avocado production doubled during the same period, from 5,099 ha in 2003 to 11,000 ha in 2013 (FAOSTAT 2013). Total avocado exports from Kenya were valued at $\$ 29.3$ million in 2013 (FAOSTAT 2013). About 85 percent of the avocado production in Kenya is achieved by small-scale farmers who grow the crop for subsistence, local markets and export (Oduol et al. 2017). Further, the avocado's contribution to food security in Kenya is also reported to be significant and its consumption is increasing as more people discover the nutritional values of this fruit. However, factors hindering the expansion of avocado production in Kenya include poor pre- and postharvest handling practices, lack of appropriate varieties and farming inputs, poor management of avocado trees, poor infrastructure, limited market information, transaction costs due to the role of middlemen, and inadequate pests and diseases control strategies (Omolo et al. 2011; Gyau et al. 2016).

Other African countries are also engaging in avocado production for export (e.g. Ghana and South Africa) and domestic consumption (e.g. Uganda) (ACET 2014). However the potential of this crop for small-scale agriculture has received little attention in the context of Africa and research has tended to focus on commercial production, and mostly in South Africa. Exploring the crop's economic and market potential to stimulate rural development, improve food security and reduce poverty is the focus of the remainder of this paper. 


\section{Context}

The commune of Giheta is located in the north of Gitega province in Burundi. Giheta has an estimated area of $155.56 \mathrm{~km}^{2}$ which is about 7.8 percent of the total area of Gitega province $\left(1978.96 \mathrm{~km}^{2}\right)$, with altitudes ranging between $1,600 \mathrm{~m}$ and $2,000 \mathrm{~m}$ and an average annual rainfall of about $1200 \mathrm{~mm}$ (PNUD/MPDRN (Ministère de la Planification du Dévelopment et de la Reconstruction Nationale) 2006, 1; PCDP (Plan Communal de Developpement Communautaire) Giheta, August 2016). ${ }^{1}$ It is one of the most densely populated communes of Gitega province with a population density of about 488 people per $\mathrm{km}^{2}$. This puts pressure on the available land for farming as agriculture is the main source of income for the majority of its population (PNUD/MPDRN (Ministère de la Planification du Dévelopment et de la Reconstruction Nationale) 2006, 12; PCDP (Plan Communal de Developpement Communautaire) Giheta, August 2016). The population of Giheta is youthful with 72 percent of its entire population under 40 year old and 40 percent under 14 year old. Like other parts of the country, Giheta was affected by the socio-political crises that Burundi has experienced and both physical and socio-economic infrastructures were destroyed.

The National Road (RN2) joins two largest cities of Burundi, Gitega and Bujumbura, and is the only tarred road in the commune. Giheta has four rural markets that each operate once or twice a week. There are no banking services or insurance companies in this commune and the absence of these important institutions makes difficult for the population to access credit and other forms of capital which they would need to improve their livelihoods.

Due to its many rivers, Giheta is well watered and this facilitates agricultural activities, allowing three agricultural seasons per annum. The main staple crops are banana, sweet potato, cassava, beans, and maize. Three types of banana are produced in Giheta, locally referred to as beer banana, cooking banana and fruit banana. Bananas are considered as one of the main sources of revenue for smallholder producers in Giheta and its total annual production averages 4,846 tons which amount to about 1.7 percent of the total banana production in Gitega province (see also Bouwmeester et al. 2009). Tree fruit production is dominated by avocados. An avocado oil firm was established in 2006 by a foreign businessman but it closed down few years later because of the insufficiency of the crop caused by local and distant market competition for avocados produced in the commune. Coffee is the only export cash crop that is produced in this commune. The entire commune has only one trained agricultural extension officer and this has significant negative impact on the transfer of knowledge and technologies for crop production.

\section{Methods}

Although not a panel study, data collection was undertaken in two waves in order to describe trends in avocado production and consumption. The first was carried out in 2009. The area was revisited in 2016 as part of a broader study looking at small-holder production in sub-Saharan Africa. Both qualitative and quantitative methods for data collection and analysis were employed, mindful of the inherent limitations of qualitative and quantitative approaches used alone as discussed by Tashakkori and Teddlie (2010) and Teye (2012). 
In-depth qualitative studies using Participatory Learning Assessment (PLA) tools such as mapping and diagrams, as well as transect walks were undertaken. ${ }^{2}$ In addition to PLA exercises, two focus group studies were conducted: one with members of a local small-scale women farmers' association which is involved in avocado seedling production and distribution in Giheta; the other with the collectors of avocados in Giheta. Further, 13 in-depth interviews were also conducted with actors along the avocado chain within and outside Giheta commune. These include political leaders involved in agricultural sector, agricultural technicians at various levels, sellers of avocados, the owner of the avocado oil firm, directors of private institutions involved in avocado production, and a medical doctor who is in charge of the health sector in this region. First, these qualitative approaches focused on the nature of avocado production and processing with special focus on at least five aspects production process, planting, harvesting, marketing, institutions, and challenges experienced by various actors in avocado chain; second, they investigate the avocados' income generation potentiality in the study area; and third, they assess the contribution of the avocados to the food security in the study area.

In addition, a non-probability questionnaire survey of 100 households was undertaken in both years. Although not sufficient to be representative of the region or commune, a random sample of 100 households were interviewed in three areas of Giheta in order to minimize selection bias. The survey instrument that was used for the quantitative component of the study was composed of two main parts.

The first section consisted of a set of questions which intend to collect the information on the households interviewed. A definition for a household used by many official statistical offices in Africa was adopted for this paper: "all persons who live together and provide themselves jointly with food or other essentials for living, or a single person living alone" (STATS SA 2017). Questions were designed to obtain different kinds of information including among other things: 1) the household composition and particulars of each person in the household. The persons considered were those who reside in the household at least four nights a week on average and have so done over a period of four weeks prior to the date of the interview. Babies and elderly people were included; 2 ) the education of each member of the household; 3 ) the employment, and all economic activities in which persons aged 15 years and above in the household are involved in; 4) the dwellings and different services that members of the household have access to such as food market, public transport, and so forth; 5) the household's assets; 6) the subsistence of the household in terms of agricultural production and other means of acquiring food for the household; 7) the living circumstances of the household, including whether the household has enough food.

The second section of the instrument focused on avocado production in the household. Questions were asked to investigate the different use of the avocados in the household, and to obtain information about the production and the production costs of avocados in the household. This section was concluded with two open-ended questions to assess the key problems and constrains associated with avocado farming in the household and the possible solutions to address those challenges.

The survey instrument in 2016 included additional questions concerning the scale of avocado production in particular and agricultural commercialization in general in the study area. This improved survey instrument has been useful in helping us gaining more 
insights into the potential impacts of smallholder avocado production in the study area in 2016. Although not representative of the commune or any other spatial area, the triangulation of two cross-sectional surveys, and the various qualitative methods provide us with the 'thick data' with which to analyse the role of avocado (Fusch and Ness 2015).

Finally, a wealth index summing the assets owned by the sampled households was used to rank individual households on a continuous scale of relative wealth from poorest to richest. $^{3}$

\section{Nature of avocado production and marketing in Giheta}

Avocados were brought by the European missionaries who arrived in Burundi in early 1920s. At this time, avocados could only be found at the missionaries centres or in the traditional chiefs' backyards. Production of this crop expanded in Giheta in the 1940s from these two sources. The farming of this new crop was then embraced by local people and expanded to such an extent that there were a significant number of avocado trees in the area by the 1960s. By the 1970s and 1980s, avocados were already sold at the local markets (Personal communication with elderly avocado producers in Giheta).

Since its advent in Giheta, avocados have predominantly been grown as backyard crops (not as commercial orchards), scattered in farms where they are intercropped with other crops. The two waves of surveys show that the households involved in farming avocados own three productive avocado trees on average. We estimate that, of the total number of 19,695 households that live in Giheta in 2017, about 13,393 households are involved in avocado production and own a total number of about 40,178 producing avocado trees which annually produce about 24,107 tons in total. ${ }^{4}$

We found that the patterns of production and marketing of avocados did not change much between the two waves of the study. The major change that we observed during the second wave of the study is the closing down of the avocado oil firm due to the lack of inputs. We had predicted this closure in the first wave in 2009 due to insufficient input. ${ }^{5}$ We also found that the nascent avocado grafting business that we saw in the first wave of the study has been unable to grow sustainably.

Avocados are normally planted in October, the month which marks the beginning of the rainy season in Burundi. Traditional avocado trees take five to six years of growth before they start to yield fruit, compared to grafted avocado trees which take a maximum of two to three years. The producers do not know the varieties of their avocados and undertake little management of their avocado trees. Only avocados which are intercropped receive some fertilization as they benefit the fertilizers applied to other crops.

Although avocado trees may flower throughout the year, the informants said that many are flowering between February and March. Fruits are harvested six months after flowering, normally between August and November. Very often, avocados of the same tree do not mature at the same time, as we found during the transect walks in the farms. This may explain why avocados can always be found at the local markets even during the off-season period. The avocado trees, however, do not yield the same amount of fruit every year and yields remain unpredictable. In general, the fully grown producing avocado tree can give a harvest of about 2 bags of avocados of $300 \mathrm{~kg}$ each. The harvesting process is left to men, specifically young male children who can easily climb the trees. Females thereafter transport the avocados to the house. For harvesting the 
avocados, small-scale farmers use a long stick to hit the fruit or use a traditional instrument locally known as "urukero" (a long stick terminated by a kind of hook). To minimize damage to the falling avocados, dried banana leaves are placed on the soil under and around the avocado trees.

The avocados are sold in three ways: either directly to consumers at the local markets, to the retailers who resell along the RN2 road or, to collectors who resell them in Bujumbura. Avocados are sold either hard or ripe. In most instances, it is women who sell the avocados. They use the money to buy products that may be needed in the household such as food and give the left over to their husbands.

Surprisingly, in 2009, farmers reported that they did not sell the avocados at the avocado oil firm of Murayi as one would expect. They cited three main reasons. First, when it started operating in Giheta, the firm sought suppliers able to provide large quantities of avocados, equal or above one ton and rejected the small quantities of avocados delivered by smallholders. Second, the firm preferred "modern" avocado varieties, such as Hass and Fuertes, rather than "traditional" ones, buying the former at $80 \mathrm{Fbu}(0,045$ US\$) per kg compared to between $40 \mathrm{Fbu}(0,022$ US\$) and $60 \mathrm{Fbu}(0,034$ US\$) per kg for "traditional" varieties. This difference in price reflected the difference in oil content, as the firm owner explained in 2009: $50 \mathrm{~kg}$ of avocados from traditional varieties were necessary to produce 1 litre of oil, whereas between 20 and $23 \mathrm{~kg}$ of the Hass or Fuertes varieties were needed to produce the same quantity. Third, the firm did not pay cash and farmers had to wait for weeks before they could get their money. All these factors have contributed to local small-scale farmers' decision to sell their avocados at the local market or to the collectors rather than selling them to the avocado oil firm of Murayi. Unsurprisingly during the second phase of the study in 2016 we found that the firm had closed down, allegedly due to the insufficient input.

\section{Avocado, income generation and living conditions in Giheta}

The smallholder avocado producers in the study area sell avocados either directly to consumers at the local markets, to the retailers who resell along the main national road or to collectors who resell them at Bujumbura. These three main marketing mechanisms have created a significant competitive local avocado market and have kept the price of the crop consistently high in the study area (see Table 1).

Smallholder avocado producers in Giheta mentioned that avocados sell well at the market and are seen as a potential source of income for many households in this area. As Table 2 indicates, avocado was reported as the main source of income in the study area just behind the banana and off-farm activities respectively. ${ }^{6}$ Bananas were also identified by the Ministry of Development Planning and National Reconstruction in Burundi as the main source of food and revenue for the population of the commune of Giheta (PCDP (Plan Communal de Developpement Communautaire) Giheta, August 2016; PNUD/MPDRN (Ministère de la Planification du Dévelopment et de la Reconstruction Nationale) 2006, 7).

Coffee was reported as the main source of income by only one percent of the sample. ${ }^{7}$ In fact, only 22 percent and 18 percent of the sample in 2009 and 2016 respectively reported that they are involved in farming coffee. The results of the PLA activities reveal that small-scale farmers are increasingly abandoning the farming of coffee and report, among other things, high costs for crop management and low revenue from the crop as 
Table 1. Avocado marketing.

\begin{tabular}{|c|c|c|}
\hline & 2009 & 2016 \\
\hline & $\begin{array}{l}\text { Percentage } \\
(\mathrm{N}=100)\end{array}$ & $\begin{array}{l}\text { Percentage } \\
(\mathrm{N}=100)\end{array}$ \\
\hline \multicolumn{3}{|c|}{$\begin{array}{l}\text { Is the total amount of avocados the household sold on the market higher, } \\
\text { lower, or more or less the same if compared with that consumed? }\end{array}$} \\
\hline Much higher & 39 & 47 \\
\hline Higher & 9 & 0 \\
\hline More or less the same & 3 & 0 \\
\hline Lower & 33 & 53 \\
\hline I don't know & 11 & 0 \\
\hline Not applicable & 5 & 0 \\
\hline \multicolumn{3}{|c|}{ Main buyers of households' avocados } \\
\hline Neighbours & 38 & 17 \\
\hline Shoppers at the local market & 25 & 17 \\
\hline Travelers (RN2) & 46 & 54 \\
\hline Collectors & 10 & 13 \\
\hline Avocado oil firm ${ }^{10}$ & 6 & - \\
\hline \multicolumn{3}{|c|}{ Whether the selling price of avocado increased for the past three years (yes) } \\
\hline & 76 & 97 \\
\hline $\begin{array}{l}\text { Whether the selling price of a } \\
\text { (Yes) }\end{array}$ & 80 & 98 \\
\hline
\end{tabular}

Table 2. Main source of income of the sampled households in 2016.

\begin{tabular}{lc}
\hline Main Source of income in the household & Percentage $(\mathrm{N}=100)$ \\
\hline Banana & 20.8 \\
Sweet potatoes & 2 \\
Avocado & 16.8 \\
Cassava & 2 \\
Off-farm activities & 19.8 \\
Vegetables & 1 \\
Livestock & 4 \\
Coffee & 1 \\
No source of cash income & 32.7 \\
Total & 100 \\
\hline
\end{tabular}

the main reasons. This is surprising since coffee is conventionally regarded as the main cash crop and source of income for small-scale farmers in Burundi (PRSP 2011).

Table 3 shows that the living conditions are more favorable for the producers of avocados in the sample than those that do not produce. The percentages of the households that own small livestock such as pigs and goats, reporting better economic status, having food, and living in houses with iron sheets or brick tiles roofing are substantially higher for the avocado producers in comparison with the households that are not involved in farming avocados.

The analysis of the household survey in the second phase ${ }^{8}$ further reveals that avocado producers are most likely to expand their land holdings (57.4 percent compared to 18.2 percent) and use hired labour (36.8 percent compared to 21.9 percent) than the households that are not involved in avocado farming. Additionally, the 2016 survey shows that the levels of agricultural input use and staple crop production are also substantially different between the households involved in avocado farming and those that are not. Table 4 indicates that the avocado producers use more than twice the quantity of fertilizer and produce more than two-fold of the quantity of maize and beans produced by the non-producers on average in the season prior to data collection. The 
Table 3. Production of avocados by some selected indicators for living conditions.

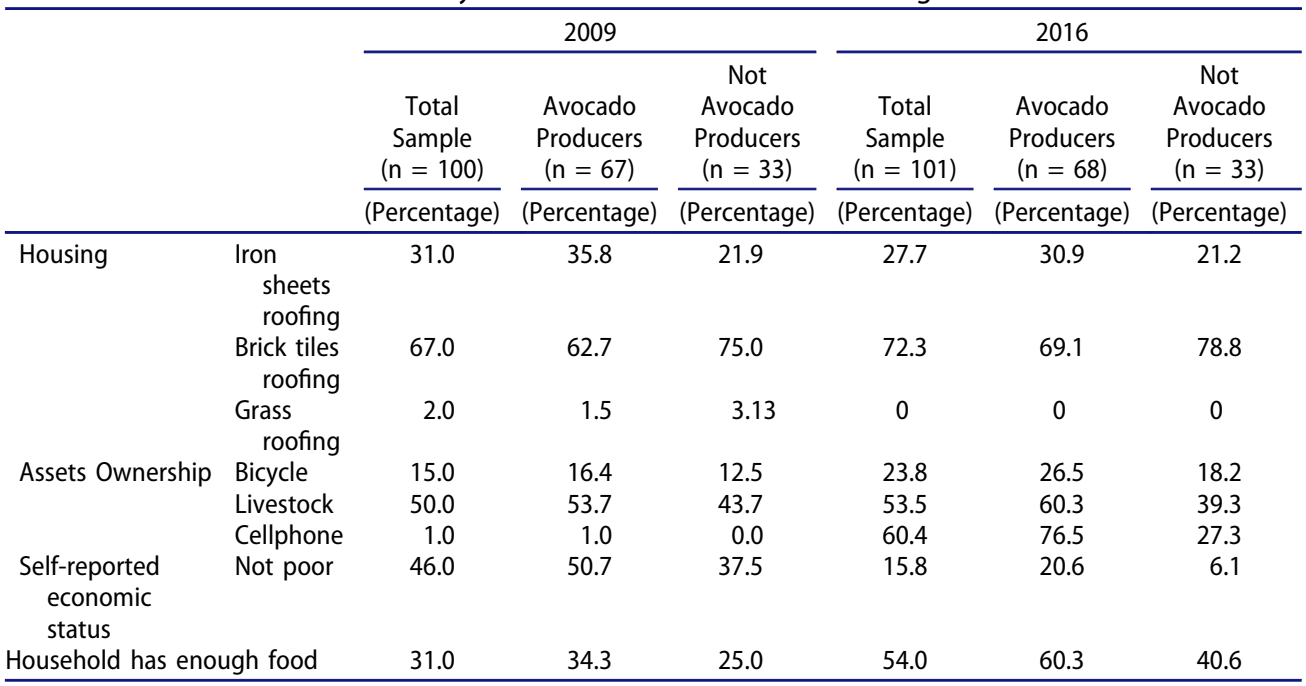

Table 4. Production of avocados and agricultural commercialisation.

\begin{tabular}{lccccc}
\hline & \multicolumn{3}{c}{2016} \\
\cline { 2 - 3 } & \multicolumn{2}{c}{ Avocado Producers } & & No Avocado Producers \\
\cline { 2 - 3 } \cline { 5 - 6 } & Mean $(\mathrm{kg})$ & Std. Dev. & & Mean $(\mathrm{kg})$ & Std. Dev. \\
\hline Quantity of fertilizer bought in the last season & 27.2 & 36.7 & & 12.7 & 15.2 \\
Quantity of maize produced in the last season & 56.2 & 60.7 & & 22.8 & 31.2 \\
Quantity of beans produced in the last season & 64.7 & 65.4 & & 31.1 & 33.2 \\
\hline
\end{tabular}

mean wealth for the avocado producing households (2.64 in 2009 and 1.69 in 2016) is higher compared to non-producers (2.27 in 2009 and 0.78 in 2016). Further, the odds that households self-report that they are not-poor are four times greater for those producing avocado than those that are not (OR 4.018, $p=0.07$ ). Nonetheless, the value of avocado produced or sold is weakly correlated (0.290 in 2009 and 0. 232 in 2016) with the wealth index.

These findings suggest a correlation between avocado production and investment in agricultural production, as well as greater wealth among avocado producers. However they need not necessarily imply causality between smallholder avocado production and better incomes. It is feasible that only better off smallholders can afford to include avocado farming as a livelihood strategy, particularly in the context of acute land shortages.

Considerable socio-economic benefits along the avocado value chain marketing were also reported in the qualitative data. One participant who had been involved in avocado production for almost 20 years commented that he managed to build a house and get married using the financial resources that he obtained from selling the avocados. Another informant, a former soldier who was demobilized at the end of the civil war, mentioned that the business provides him with money that he uses for paying the farm workers who work on his farm and the financial capital that he uses for doing other small businesses which also generate income. 
This contribution seems, however, to be not well understood by the political leaders that were interviewed. They commented only on the role of avocados for the households' consumption and seem to be unaware of the role avocados play in increasing the income of small-scale farmers. The failure to detect the shift in the interests of smallscale farmers from traditional cash crop such as coffee to new emerging crops such as avocados may carry significant opportunity costs given the economic potential of this crop and its possible pro-poor outcomes.

\section{Avocado and food security in Giheta}

The household surveys show that avocados are widely consumed and regarded as a beneficial addition to the diet of households in the study area. Table 5 indicates that the consumption of avocado among all categories of the sampled households' members is widespread (frequent at around 4 times per week in 2009 and 6 times per a week in 2016). Local people like its taste and thus have easily incorporated it into their diet. The fruit is consumed in many different ways; either with other food or consumed alone. The majority of the sample (87.0 percent and 82.3 percent in 2009 and 2016 respectively) indicates that they consume avocados with other food. Local people prefer to use the avocados with other food because they add taste to these basic foods as a result of the quantity of oil contained in the avocado, serving as the "butter of the poor" (OnyangoObbo 2011). In many instances, avocados are even used to substitute cooking oil which a significant number of the local people cannot afford. Moreover, due to food insecurity issues in the area (Collins et al. 2013), families cannot afford to have two types of food to complete their meal and therefore use avocados to substitute the type of food that they do not have. This feature gives avocados more preference over the other types of fruits produced in Giheta.

The frequent consumption of avocados suggests that the contribution of this fruit to the diet of the sampled households is significant and can subsequently contribute towards the improvement of the food security and health of the sampled households' members given its nutritional value. In the context of Burundi, avocados do not have a high calorie cost relative to other staples, and are also valued for the variety they contribute to the diet and their taste. Our study does suggest some evidence of this given the qualitative responses that note the desire for avocado due to its taste. However, we do not have sufficient information to assess the diets of the respondents and thus the comparative contribution of avocado relative to other staples, such as banana, cassava, sweet potato and beans.

In addition, to demonstrate the importance of avocado production for food security, a logistic regression was employed to predict the probability that the household's avocado consumption would have an impact on child hunger. The model controls for

Table 5. Use of avocados in the household's diet.

\begin{tabular}{lcr}
\hline & 2009 & 2016 \\
\cline { 2 - 3 } & (Percentages) & (Percentages) \\
\hline Adult members in the household eat avocadoes & 90.0 & 98.0 \\
Children in the household eat avocadoes & 95.0 & 100.0 \\
Avocados are consumed with other food & 87.0 & 82.3 \\
\hline
\end{tabular}


confounders that influence the likelihood of avocado consumption. These include the number of assets, household size, sex of the head of household, the age of the head of household, ownership of land, other farming activities taking place such as horticulture, livestock, and coffee. The dependent variable was derived from the question: "in the past 12 months, did a child, 17 years old or younger, in the household ever go hungry because there was not enough food", and the independent variable of interest was "whether any household members consumed avocados in the last 12 months". The former is a widely used instrument adopted for the measurement of food security and was coded as $1=$ never and $0=$ often and the latter was coded as $1=$ yes and $0=$ no. The logistic regression model is expressed as follows:

$$
\mathrm{Y}=\mathrm{a}+\mathrm{b}_{1} \mathrm{X}_{1}+\mathrm{b}_{2} \mathrm{X}_{2} \ldots \mathrm{b}_{n} \mathrm{X}_{n}+\mathrm{e}
$$

Where $Y$ represents the predicted value of the dependent variable, $a$ is a constant, $X_{1}$, $X_{2, \ldots} X_{n}$ represent the values of independent variables, $b_{1}, b_{2} \ldots b_{n}$ represent the regression coefficients; and e represents the margin of error. The results are shown in Table 6 ( $\mathrm{n}=98$ in 2009 and $\mathrm{n}=98$ in 2016).

Employing a 0.10 criterion of statistical significance, Table 6 shows that avocado consumption is a significant predictor of the absence of child hunger ( $p=0.039$ in 2009 and 0.077 in 2016). Additionally, a positive coefficient of avocado consumption (9.287 in 2009 and .110 in 2016) suggests that the avocado consumption positively influences the probability of the absence of child hunger in the sampled households, either directly through the consumption of the child, or indirectly by freeing up other food sources when adults consume avocado. Table 6 further shows that the sex of the head of the household also makes a difference as the male-headed households (.851 in 2009 and 1.271 in 2016) tend to be less likely to experience child hunger in comparison to the female-headed households, holding all other predictors constant, including wealth measured as a count of household assets. We repeated this analysis using the sale of avocado as the independent variable of interest, and found a similar result, although with a weaker, but still significant coefficient.

\section{Conclusion}

This paper set out to investigate the contribution of avocados to the income generation, food security and living conditions of small-scale farmers in Giheta, Burundi. The results

Table 6. Relationship between child hunger and avocado consumption.

\begin{tabular}{|c|c|c|c|c|c|c|c|c|}
\hline \multirow[b]{2}{*}{ Predictors } & \multicolumn{4}{|c|}{2009} & \multicolumn{4}{|c|}{2016} \\
\hline & $\begin{array}{l}\text { Odds } \\
\text { Ratio }\end{array}$ & $\begin{array}{l}\text { Std. } \\
\text { Err. }\end{array}$ & $\begin{array}{c}Z \\
\text { Value }\end{array}$ & $\begin{array}{c}P \\
\text { Value }\end{array}$ & $\begin{array}{l}\text { Odds } \\
\text { Ratio }\end{array}$ & $\begin{array}{l}\text { Std. } \\
\text { Err. }\end{array}$ & $\begin{array}{c}Z \\
\text { Value }\end{array}$ & $\begin{array}{c}P \\
\text { Value }\end{array}$ \\
\hline Size of the household & .575 & .095 & --3.36 & 0.001 & .927 & .122 & --0.58 & 0.564 \\
\hline $\begin{array}{l}\text { Sex of the head of the household } \\
(0=\text { Female; } 1=\text { Male })\end{array}$ & .851 & 1.110 & --0.12 & 0.902 & 1.271 & .707 & 0.43 & 0.666 \\
\hline Age of the head of the household & 1.086 & .032 & 2.78 & 0.005 & .988 & .017 & --0.68 & 0.498 \\
\hline Number of owned assets & 2.845 & 1.237 & 2.40 & 0.016 & 1.905 & .475 & 2.58 & 0.010 \\
\hline Horticulture farming & .709 & .444 & --0.55 & 0.582 & 4.839 & 5.734 & 1.33 & 0.183 \\
\hline Livestock farming & 6.800 & 5.222 & 2.50 & 0.013 & 1.088 & .524 & 0.17 & 0.861 \\
\hline Coffee farming & 3.045 & 2.493 & 1.36 & 0.174 & 3.616 & 2.424 & 1.92 & 0.055 \\
\hline Avocado consumption & 9.287 & 10.013 & 2.07 & 0.039 & .110 & .138 & --1.77 & 0.077 \\
\hline Ownership of land & 6.250 & 8.237 & 1.39 & 0.164 & 1.031 & .094 & 0.34 & 0.735 \\
\hline Constant & .000 & .000 & --3.52 & 0.000 & 7.061 & 11.191 & 1.23 & 0.217 \\
\hline
\end{tabular}


of the qualitative approach and the household surveys carried out in 2009 and in 2016 suggest that the avocado sector in Giheta has consistently been a worthwhile activity for small-scale farmers. Our results show that avocados are well-known and widely consumed in Giheta and that households that consume, or sell avocados are less likely to experience child hunger than those that do not, even when household wealth is controlled for. The implication of this is that the contribution of avocados to their diet and the documented associated positive effects to their health are potentially significant and important. In this logic, the case of avocado crop demonstrates the potential for a crop to be used for domestic consumption and sale, which in time, could be exported or further processed as a cash crop.

However the avocado value chain in Giheta remains largely one in which subsistence farmers are selling surplus crops in a limited national market and there are substantial inefficiencies along the chain with wastage, poor institution support and virtually no quality improvement or beneficiation. As a result, small-scale farmers have not yet been able to reap substantial benefits from avocados as the levels of per capita income from avocados remain low.

In order to increase the capacity of avocado production in this area and subsequently enabling small-scale farmers to gain a greater income from this sector, the avocado sector requires a viable and supportive environment. This could consist of, among other things, the increase of the assets of rural poor households, especially a more equitable land distribution; making small-scale farmers more productive through providing them with farming skills and other inputs they need for farming, and creating opportunities in the rural non-agricultural economy through support for non-agricultural livelihoods and effective and viable rural infrastructural development. All these require a significant intervention of the government and strong commitment of political leaders involved in agricultural sector to promote avocado farming not only in Giheta but also in other parts of the country where this crop can grow. The current president of Burundi has tried to promote avocado production at the national level but his efforts were overshadowed by many other competing priorities in the post-conflict period. The office of the President nevertheless estimates that eight million trees had been planted between 2009 and 2015. ${ }^{9}$ Such commitment will only be possible if there is wider political support of the economic opportunities that this crop presents to the income generation and food security for the small-scale farmers and its potential to diversify the farming of cash crops in Burundi.

\section{Notes}

1. All information in this section is coming from these two references.

2. The qualitative component was not repeated in 2016.

3. https://dhsprogram.com/topics/wealth-index/index.cfm.

4. Our estimates are based on the information that we obtained from the document that sets out the socio-economic medium-term development plan of the Commune of Giheta called "Plan Communal de Développement Communautaire"(http://www.provincegitega.gov.bi/ Documents/PCDC\%20I1\%20GIHETA\%20FINAL.pdf) and from both qualitative and quantitative data.

5. http://researchspace.ukzn.ac.za/xmlui/bitstream/handle/10413/7722/Hakizimana_Cyriaque_ 2011.pdf?sequence=1\&isAllowed=y. 
6. This question was not included in the survey instrument that was used in the first phase hence we are unable to compare the households' source of income in 2009 and 2016. However, the information about the source of income was collected in the qualitative studies in 2009 and, of the eleven households that were interviewed; avocados were reported as the main source of income for eight households. Of course one needs to bear in mind that the households that participated in the qualitative studies in the first phase were purposefully selected on the basis that they are involved in avocado production.

7. In the qualitative studies in 2009 ( $n=11$ ), coffee, the main cash crop in Burundi, was reported as the main source of income in only one household.

8. The survey instrument used in 2016 included questions on agricultural commercialisation that were not included in the first phase in 2009.

9. http://www.monitor.co.ug/News/Insight/Will-avocado-and-sport-keep-Burundi-alive/ 688338-1514476-jq8vsc/index.html.

10. This category was dropped in the 2016 survey instrument because the avocado oil firm was no longer in operation.

\section{Funding}

This work was supported by [National Research Foundation of South Africa]', '[UID: 91490].

\section{References}

AGRA. 2011. What is the Alliance for a Green Revolution in Africa? [accessed 2017 Jul]. www.agraalliance.org.

ACET. 2014. 2014 African transformation report: growth with depth. Accra: African Center for Economic Transformation.

Barrett BC, Christiansen LD, Sheahan M, Shimeles A 2017. On the structural transformation of rural Africa. World Bank policy research working paper 7938. World Bank, Washington D.C.

Beegle K, Christiaensen LD, Gaddis I. 2016. Poverty in a rising Africa. Washington D.C: World Bank.

Bouwmeester H, Pja VA, Ouma EA. 2009. Mapping key variables of banana based cropping systems in the great lakes region: partial outcomes of the baseline and diagnostic surveys. Ibadan: International Institute of Tropical Agriculture.

Chen LB, Liao SY. 2015. The role of agricultural productivity on structural change. Rev Dev Econ. 19 (4):971-987.

Christiaensen LD, Kaminski J 2015. Structural change, economic growth and poverty reduction: micro-evidence from Uganda. Working Paper Series 229. African Development Bank, Abidjan.

Collier P, Dercon S. 2014. African agriculture in 50 years: smallholders in a rapidly changing world? World Dev. 63(11):92-101.

Collins C, Magnani R, Ngomirakiza E. 2013. USAID office of food for peace: food security country framework for Burundi (FY 2014-FY 2019). Washington. DC: USAID.

Davis B, Di Giuseppe S, Zezza A 2014. Income diversification patterns in rural Sub-Saharan Africa: reassessing the evidence. Working Paper 7108. World Bank, Washington DC.

De Janvry A, Sadoulet E. 2010. Agricultural growth and poverty reduction: additional evidence. World Bank Res Obs. 25(1):1-20.

De Souza APJ. 2015. Evidence of growth complementarity between agriculture and industry in developing countries. Structural Change Econ Dyn. 34:1-18.

FAOSTAT. 2013. World food and agriculture. Rome: Food and Agriculture Organization of the United Nations.

Fusch PI, Ness LR. 2015. Are we there yet? Data saturation in qualitative research. Qual Rep. 20 (9):1408-1416. 
Gyau A, Mbugua M, Oduol J. 2016. Determinants of participation and intensity of participation in collective action: evidence from smallholder avocado farmers in Kenya. J Chain Netw Sci. 16 (2):147-156.

Hakizimana C, Goldsmith P, Nunow AA, Roba AW, Biashara JK. 2017. Land and agricultural commercialisation in meru county. Kenya: evidence from three models. J Peas Stud. 44(3):555-573.

Human Development Report. 2016. Human development for everyone. New York: United Nations Development Programme.

Johnston BF, Mellor JW. 1961. The role of agriculture in economic development. Am Econ Rev. 51 (4):566-593.

Larson FD, Otsuka K, Matsumoto T, Kilic T. 2014. Should African rural development strategies depend on smallholder farms? An exploration of the inverse productivity hypothesis. Agric Econ. 45:355-367.

Lewis WA. 1954. Economic development with unlimited supplies of labour. Manchester Sch Econ Soc Stud. 22(2):139-191.

Matenga RC, Hichaambwa M. 2017. Impacts of land and agricultural commercialisation on local livelihoods in Zambia: evidence from three models. J Peasant Stud. 44(3):574-593.

Mwambi MM, Oduol J, Mshenga P, Saidi M. 2016. Does contract farming improve smallholder income? The case of avocado farmers in Kenya. J Agribusin Devel Emer Eco. 6(1):2-20.

Oduol JBA, Mith€Ofer D, Place F, Nang'ole E, Olwande J, Kirimi L, Mathenge M. 2017. Women's participation in high value agricultural commodity chains in Kenya: strategies for closing the gender gap. J Rural Stud. 50:228-239.

OECD. 2017. Agricultural policy monitoring and evaluation 2017. Paris: OECD Publishing.

Omolo P, Tana P, Mutebi C, Okwach E, Onyango H, Okach K. 2011. Analysis of avocado marketing in trans-nzoia district, Kenya. J Dev Agric Econ. 3(7):312-317.

Onyango-Obbo C 2011. Burundi: Nkurunziza, the 'avocado president'. [accessed 2018 Aug]. http:// allafrica.com/stories/201107181122.html.

PCDP (Plan Communal de Developpement Communautaire) Giheta, August 2016. This document was obtained from the administrator of Giheta district.

Perez-Jimenez MR. 2008. Significant avocado diseases caused by fungi and oomycetes. Eur J Plant Sci Biotechnol. 2(1):1-24.

PNUD/MPDRN (Ministère de la Planification du Dévelopment et de la Reconstruction Nationale). 2006. Monographie de la Commune Giheta. [accessed 2017 Jul]. http://decentralisation.gov.bi/ pcdc\%20comm/gitega/MonoGiheta.pdf.

PRSP. 2011. Burundi Poverty Reduction Strategy Paper: Progress Report. International Monetary Fund, Washington D.C.

Rodríguez-Carpena JG, Morcuende D, Estévez M. 2011. Avocado, sunflower and olive oils as replacers of pork back-fat in burger patties: effect on lipid composition, oxidative stability and quality traits. Meat Sci. 90:106-115.

Schultz TW. 1964. Transforming traditional agriculture. New Haven: Yale University Press.

STATS SA. 2017. Living conditions of households in South Africa: an analysis of household expenditure and income data using the LCS 2014/2015. Pretoria: Statistics South Africa.

Tabeshpour J, Razavi BM, Hosseinzadeh H. 2017. Effects of avocado (Persea americana) on metabolic syndrome: a comprehensive systematic review. Phytotherapy Res. 2017:1-19.

Tashakkori A, Teddlie C. 2010. Putting the human back in human research methodology: the researcher in mixed methods research. J Mix Methods Res. 4(4):271-277.

Teye JK. 2012. Benefits. Challenges, dynamism positionalities associated with mixed methods research developing countries: evidence ghana. J Mix Meth Res. 6(4):379-391.

Yaro AJ, Teye JK, Torvikey GD. 2017. Agricultural commercialisation models, agrarian dynamics and local development in Ghana. J Peasant Stud. 44(3):538-554. 